\title{
Olympics and Rule 40: A Critical Examination
}

\author{
Vidhi K Tiwari* and Suman Setty†
}

\section{Abstract}

The most awaited event in the world of sports has given rise to a controversy, following the recent amendment in the form of the much discussed, Rule 40, of the Olympic Charter. This move has been criticized due its various drawbacks. In the wake of the same, an attempt has been made to critically examine the situation, considering the aspects of commercial marketing, intellectual property attributes relating to the event, rights of athletes and most importantly the effective implementation of this rule. In the London Olympics, rule 40 had secured a mention due to the protests initiated by athletes, on various public platforms. In furtherance of a critical evaluation, controversies have been summarized and examined. In the effort to depict the failed attempts at bringing about a harmonious balance between rights of athletes and getaways available to the independent sponsors, possible impacts in various dimensions have been addressed. The recent advertisement campaign of Nike, which holds the potential of initiating proceedings against an Indian hockey player, Rani Rampal, has also been assessed. The

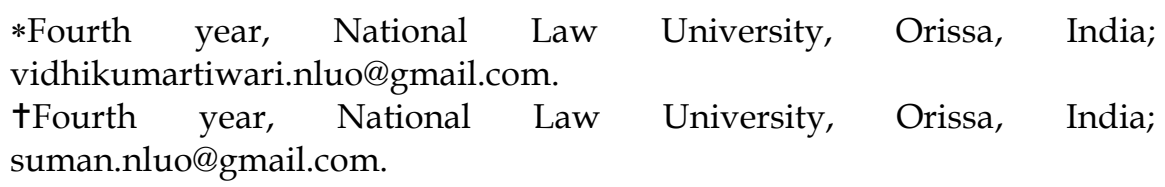


article concludes with highlighting a crucial need for considering the controversies emerging because of Rule 40.

Keywords: Ambush Marketing, Commercial Advertising Deemed Consent, Rule 40, Olympics.

\section{Introduction}

In February 2015, the International Olympic Committee (IOC) had taken the decision to relax its stringent guidelines under Rule 40 of the Olympic Charter. The Committee decided to allow "generic" or "non-Olympic advertising" during the 2016 Summer Games. Additionally, the athletes were allowed to post on social media about non-official sponsors, only if they did not use any of the Olympic properties and references. This controversial rule was established to prevent over-commercialization and to protect those Olympic sponsors who invest large sums of money in acquiring exclusive marketing rights during the event. This rule effectively prevents hawking by non-official sponsors. The rule states that non-official sponsors cannot associate with Olympics on any of the social media platforms or through any other medium.

The basis of this rule is to disallow any sort of association with Olympic Games and to prevent ambush marketing. As defined by the IOC, ambush marketing is a planned attempt by a third party to associate itself directly or indirectly with the Olympic Games in order to gain the recognition and benefits associated with being an Olympic partner. ${ }^{1}$ It is a strategy used by the advertisers to associate themselves with the games, without paying a sponsorship fee. According to this rule, an athlete's image cannot be used to promote a brand or sell products of a company, but the official sponsors of the event i.e. Coca-Cola, McDonalds, etc., are exempted from this rule. Even a simple message of support for the athlete, who is competing in the Olympics, would constitute a violation of Rule 40, which would result in harsh penalties such as disqualification and stripping off the medals of a participant.

1 James L. Bikoff, The Olympic Brand Protection: Challenges in London 2012, 106 Am. Soc'y Int'l L. Proc. 99, 99-102 (2012). 


\section{Evolution of the controversial rule}

The Olympic Charter is a 110 page cohesive document which contains all of the rules and regulations that must be followed in connection with the Olympic Games. It is a comprehensive text focusing on all relevant aspects including the minute details of the event itself. Rule 40 of this Charter lays down the required conditions for participation in the Games, which includes:

Except as permitted by the IOC Executive Board, no competitor, coach, trainer or official who participates in the Olympic Games may allow his person, name, picture or sports performances to be used for advertising purposes during the Olympic Games.

The interpretation of the rule suggests that the initial aim was to ensure the 'amateur' status of the athletes. This rule has developed with time and today it stands for combating ambush marketing and protecting the official sponsors and partners of the Games by limiting third parties from hawking on their exclusive marketing rights. This reflects the IOC's essential concern to singularly protect and promote the brands they are associated with. Rule 40 prohibits athletes from agreeing to appear in all forms of advertising for a short period before and during the event, without permission of the IOC. ${ }^{2}$

\section{History of Rule 40}

Violation of Rule 40 can be traced back to the year 2002 when snowboarder, Danny Kass, was asked to remove his poster from a store, to compete in the Half-Pipe final. ${ }^{3}$ In 2010, snowboarder Shaun White's Target advertisement in the Times Square, was blacked out because the retailer was not an official Olympic partner. In 2012, at the London Olympics, athletes on social media expressed their inability to reward the sponsors due to the efforts

${ }^{2}$ Alex Kelham,Navigating Olympic Advertising: Rule 40-A Global Perspective(Aug. 4, 2016), http:/ / www.lawinsport.com.

${ }^{3}$ Lori Shnontz, Olympic Rule leaves non-sponsors with few words (July 27, 2016), http://www.runnersworld.com/olympics/olympic-ruleleaves-non-sponsors-with-few-words. 
made by the IOC to protect its official sponsors through this controversial rule.

In 2015, the IOC made changes in the restrictions under Rule 40. It now allowed non-Olympic sponsors to advertise during the blackout period, until there is a waiver application approved by the Committee or through deemed consent. Though relaxing, changes were made in Rule 40, 'the list of inadmissible practices' still stood unchanged and included 20 words and phrases that would constitute a violation of Rule 40. There is no provision for punishment and penalty under Rule 40. The disciplinary procedures for any violations are laid down under Rule 59 of the Charter which prescribes for the revocation of medals, loss of credentials and disqualification from the Games.

\section{London Olympics}

In the 2012 London Olympics, there was a major movement against unauthorized commercial association with the Olympic Games and ambush marketing. This was made possible with the passage of a special legislation i.e. the London Olympic Games and Paralympic Games Act 2006, which was passed after London won the bid to host 2012 Olympic Games. This legislation was more stringent than the Olympic Symbol etc. (Protection) Act 1995, as it prevented all kinds of unauthorized association with the Games. Under this Act, advertisements comprising of images of London, combined with any images having thematic relation to the Olympic Games, was prohibited. Although the law is no longer applicable, the companies still need to be careful with their associations.

\section{Critique of the rule}

Famous competitors in the London Games, Galen Rupp and Mary Cain, were under the training programme of the Nike Oregon Project. This Project paid dividends in the London Olympics, where Rupp had participated. He was not allowed to give regards to his sponsor, Nike, as it was not an official partner of the Games. Few other competitors also criticized this law, as they felt that their ability to promote themselves was being restricted at a time when they were most visible. 
The relaxation given, post the London Olympics, was indeed applauded by the athletes across the world. The benefit of the new amended policy is said to be in the favor of the non-sponsors and athletes, who now would be able to generate a financial outcome, even during the Olympic Games. However, the amendments made to Rule 40 are not free from the clutches of controversy. The change, has instead, created a vacuum, as far as procedural and technical implementations are concerned.

\section{Creaking Controversies}

With the relaxation of Rule 40, a new debate has arisen. The IOC is famous for its rigid approach when it comes to the intellectual property attributes of the Games. ${ }^{4}$ Legal experts across the world are doubtful if generic terms like Gold, Silver and Victory, along with other prohibited words in the list can be granted protection. ${ }^{5}$ Further, the action to be taken against an independent private party which has no direct association with Olympic Association is questionable. Recently, letters showing objections were issued to many companies by USOC, but the penalties for independent parties violating the rule, are nowhere mentioned. The second controversy is regarding the encroachment on the monopoly of the Olympic sponsors. Before the amendment was implemented, only Olympic sponsors could advertise and benefit from the event in return for a huge investment. With this change, even non-sponsors were made eligible to exploit the happenings of the event with certain conditions in place. Some factions have opined that it is unfair to the Olympic sponsors that independent parties with minimal investments also get a big share of prospective opportunities. Furthermore, it also decreases the value associated with Olympic Sponsorship.

\footnotetext{
${ }^{4}$ Chris Chavez, What is Rule 40? The IOC's rule on non-Olympic sponsors (July 25, 2016), http:/ / www.si.com.

${ }^{5}$ IOC, Rule 40 Q and A (August 2, 2016), https:/ / www.olympic.org
} 


\section{Athletes' Losses}

It would be important to mention here, that Rule 40 is not the athletes' favorite either. Even after being amended, it continues to be the subject of sorrow for majority of the athletes. The amended rule continues to impose restrictions in the parallel world of social media, when it comes to the public display of affiliation by the athletes and the private sponsors who are not fortunate enough to get the Olympic sponsorship.

National Olympic Associations are responsible for implementing the Rules and the stand taken by the Indian Olympic Association indicates a neutral stance towards Rule 40. If the practice world over is to be looked upon, the repercussions of violating Rule 40, can be a costly affair for an athlete, as the penalties awarded therein may include stripping the athletes off their medals and banning them from participating in the future. Herein lies the biggest controversy of the subject matter at hand, where the rights of the athletes also step into the frame. Questions are raised about the redundancy of traditions dating back to 1800, which have led to a prohibition of marketing. Athletes have advanced the logic that Olympic Games is the biggest event during which the value of an athlete is the highest. By imposing the blackout period blanket, IOC is affecting their financial earning capacity and their ability to gain public recognition, by reducing their visibility vis-à-vis the advertisements.

An even more complex question is the one regarding the responsibility of such violations not being scaled. The penalties imposed are regardless of the control of the athlete over the activities of the sponsor. The effectiveness of the actions taken against the sponsor can very much be considered to be in deep shadows. Another technical aspect which is worth mentioning is that the procedure of the waiver is required to be filed months before the event takes place - at a time when participants have not even been chosen for the Olympics. It is not viable for the sponsors to gamble with their investments. This impacts the first time participants, who are not famous, but are in need of the sponsorship. There have been contentions supporting the antitrust 
rights of athletes by not allowing them to take the benefit of the event, not to forget that careers in sports are relatively short.

\section{Adopting Creative Alternatives}

The restrictions put under amended Rule 40 do not seem to be as effective as intended. Independent sponsors have found different ways to pass the package. The most suitable example would be the Under Armour's 'Rule yourself Campaign'. It features Michal Phelps and the US Gymnastic team, both being participants in Rio Olympics. In one video clipping, Phelps is shown preparing for a competition. It does not take too much for an individual to connect the dots and to understand that the event Phelps is preparing for, is the Olympics and that Under Armour is sponsoring him. With proper filing of waiver, non-usage of prohibited terms and compliance of time line, Under Armour has successfully proven that where there is a legal hurdle, there surely is a way to bypass it, while also profiting from the same. The campaign is valid on all technical and legal grounds. Under Armour also intends to set up workout centers for spectators in Olympics. It would be an interesting part of the entire event in terms of testing waters of the limits of Rule 40.

The Indian Olympic Association has taken an inert stand on Rule 40, which might save it from having to resolve conflicting situations. This is not a new concept in India as ICC tournaments are governed by similar rules of association. The proposal of inclusion of cricket as a sport in Olympics has been made and if supported, in 2024 Olympics, India will be well equipped to handle the situation. It will be helpful to decide the policy beforehand as our cricket players indeed make a fortune out of commercial endorsements.

\section{Conclusion}

The change in Rule 40 has received mixed responses from diverse sets of stakeholders and classes. The intention behind its incorporation is protected as no waiver concerning exclusive intellectual property would ever possibly gain consent from any Olympic Association. The shadow of this rule has 
multidimensional impacts including those on athletes and official sponsors. Although this rule affects big brands and companies, it is the smaller companies and contract opportunities for athletes that suffer the most. The rule especially puts a harsh burden on athletes who are less-known and can only garner public recognition during the Olympics.

The sponsors who can achieve the maximum benefit out of their investment on an athlete, are those who, at an early stage, have strategized and secured their waiver and consent approvals. It can be said that a comparatively liberal approach has been taken and with the passage of time and events, it stands a fair chance of development. After the 2016 Games, prospective and current sponsors, agents and athletes will still be analyzing the effects of the changes under the strict provision of Rule 40. This issue becomes crucial for India due to the proposed inclusion of cricket, in Olympics. A similar policy was opposed by cricket players in the domestic sphere. In the ongoing event as well, the Rani Rampal issue has sufficient potential of attracting some reactions in addressing policy reform. India should be ready to take active part in further policy formation on the same subject. 